\title{
New insights into the behavior of lithium isotopes in the clay-size fraction of marine sediments
}

\author{
CHARLOTTE LÄUCHLI ${ }^{1}$, NESTOR GAVIRIA-LUGO ${ }^{2}$, \\ ANNE BERNHARDT $^{1}$, HELLA WITTMANN ${ }^{2}$, DIRK \\ SACHSE $^{2}$ AND DR. PATRICK J. FRINGS ${ }^{2}$ \\ ${ }^{1}$ Free University of Berlin \\ ${ }^{2}$ GFZ German Research Centre for Geosciences
}

Presenting Author: charlotte.laeuchli@fu-berlin.de

Quantifying rates of weathering processes is important to constrain the long-term carbon cycle and the evolution of Earth's climate. The hydrolysis of silicate minerals at the Earth surface, influenced by precipitation, temperature and therefore atmospheric $p \mathrm{CO}_{2}$, causes a net removal of carbon from the atmosphere. This negative feedback is necessary to maintain the long-term balance in the global carbon budget. However, the exact nature of the relationship between climate and weathering, as well as the timescales and efficiency of the weathering feedback, remain subject to debate. Using marine sedimentary series from active margins as paleo-records, characterized by high resolution and high preservation potential, can help shed light on these complex interactions.

One of the most promising proxies for weathering intensity is the ${ }^{7} \mathrm{Li} /{ }^{6} \mathrm{Li}$ ratio (expressed as $\delta^{7} \mathrm{Li}$ ) because of its large fractionation during secondary mineral formation. While $\delta^{7} \mathrm{Li}$ of river dissolved $\mathrm{Li}$ is reasonably well studied, $\delta^{7} \mathrm{Li}$ in secondary clays and their behavior during sediment deposition has received much less attention. Questions remain regarding their interpretation in marine settings. In particular, little is known about the possible buffering of terrestrial weathering signals in clays during transport from source to sink, alteration of $\delta^{7} \mathrm{Li}$ during early diagenesis or the effects of imperfect separation of primary minerals in the clay-size fraction of the sediments.

Here, we tackle these questions with a dataset encompassing river sediments, their corresponding marine surface sediments and paleo-records from depth profiles of gravity cores at three sites along the Chilean active margin. These sites, located at $30^{\circ} \mathrm{S}, 33^{\circ} \mathrm{S}$ and $36^{\circ} \mathrm{S}$ span a large climatic gradient from semiarid to humid temperate zone and cover the age interval from $20000 \mathrm{yr}$ BP to present-day. Our first isotopic and compositional results from the exchangeable fraction (extracted using ammonium chloride) suggest that $\mathrm{Li}$ in interlayer sites quickly equilibrates with seawater, with a fractionation of around $-30 \%$. More surprisingly, the $\delta^{7} \mathrm{Li}$ of the silicate residual fraction of the clay-sized separates shows a pronounced increase from continental to marine samples. The terrestrial weathering intensity signal might thus be systematically overprinted by shallow diagenetic processes taking place in the marine realm. 